\title{
Transferências e mediações culturais nas Américas: o papel da Nueva Revista de Buenos Aires (1881-1885)
}

\author{
Paula da Silva Ramos ${ }^{1}$
}

\begin{abstract}
Resumo: este artigo está pautado na discussão dos cruzamentos culturais e políticos que incidiram sobre o meio intelectual argentino na década de 1880 . Nesta proposta, entendemos a Nueva Revista de Buenos Aires (1881-1885) enquanto um campo de interlocução entre os intelectuais latino-americanos e Vicente Quesada e Ernesto Quesada, diretores e proprietários do mensário. Sustentamos também que ambos desempenharam a função de mediadores culturais na medida em que atuaram para conformar, por meio de suportes materiais e de relações sociais, a circulação e apropriação de ideias no continente. Com base em tais pressupostos visamos caracterizar a rede de sociabilidade construída entre Vicente e Ernesto Quesada e os colaboradores da Nueva Revista de Buenos Aires, com destaque à figura do romancista brasileiro Franklin Távora, a fim de identificar os pontos de intersecção das aspirações dos homens de letras dos diversos países do continente, atento às perspectivas de aproximação e à discussão acerca do lugar que deveria ser ocupado pela cultura latinoamericana no cenário mundial.
\end{abstract}

Palavras-chave: transferências culturais; América Latina; século XIX.

\section{Transfers and cultural mediations in the Americas: the role of the Nueva Revista de Buenos Aires (1881-1889)}

\begin{abstract}
This article is based on discussion of the cultural and political interconnections in the Argentine intellectual circles in 1880s. In this proposal, the Nueva Revista de Buenos Aires (1881-1885) is understood as a forum for dialogue between Latin American intellectuals and Vicente and Ernesto Quesada, directors and owners of the magazine. And both were cultural mediators, affording, through material support and social relations, circulation and appropriation of ideas on the continent. Based on these assumptions we aimed to characterize the sociability network built between Vicente and Ernesto Quesada and the collaborators of Nueva Revista de Buenos Aires, with emphasis on the Brazilian novelist Franklin Távora, in order to identify the intersection points of the aspirations of men of letters from various countries of the continent, with special attention to approach prospects and the discussion about the place that should be occupied by the Latin American culture on the world stage.
\end{abstract}

Keywords: Cultural Transfers; Latin America; 19th century.

\footnotetext{
${ }^{1}$ Doutoranda em História no Programa de Pós-Graduação da Faculdade de Ciências e Letras de Assis - UNESP Universidade Estadual Paulista, Campus de Assis. Este artigo é parte da pesquisa em andamento intitulada Forjando a nação argentina: política, cultura e identidade na Nueva Revista de Buenos Aires (1881-1885), financiada pela CAPES. E-mail: ramosps.his@gmail.com
}

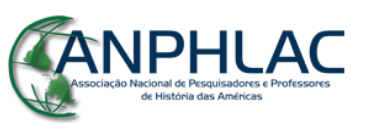


Artigo recebido em: 17/02/2016

Artigo aprovado para publicação em: 17/05/2016

A Nueva Revista de Buenos Aires foi um importante canal de interlocução entre os intelectuais latino-americanos no final do século XIX. Por meio dela, Vicente e Ernesto Quesada, diretores e proprietário do mensário, desempenharam a função de mediadores culturais na medida em que atuaram para conformar, a partir de suportes materiais e de vínculos sociais, a circulação e apropriação de ideias no continente.

Michel Espagne (1999), estudioso das relações entre Alemanha e França, utilizou-se do conceito de mediadores culturais, ou passeurs culturels, para explicar o papel dos agentes que interligavam distintos sistemas culturais, destacando a função do tradutor, figura que colaborava para aproximar e introduzir elementos de uma cultura na outra. É importante observar, porém, que a transmissão realizada por um passeur não é neutra, pois neste processo interagem variáveis que permeiam suas ações, tais como o repertório cultural, projeto político e o círculo de sociabilidades intelectuais. No que diz respeito à abordagem da produção e das transferências culturais viabilizadas por Vicente e Ernesto Quesada, pautamo-nos em três níveis de análise que se referem aos suportes materiais, às instâncias de mediação e aos usos e às práticas que conformaram a recepção.

A análise da Nueva Revista de Buenos Aires, enquanto suporte à circulação de ideias no contexto latino-americano, supõe considerar as questões que se interpuseram entre o texto produzido pelo autor e a materialização da obra, que dizem respeito às relações editoriais, mercadológicas e aos recursos financeiros para a manutenção do empreendimento. Observamos também a maneira como se davam os contatos e os critérios de seleção dos colaboradores e correntes literárias a serem veiculadas pela revista, bem como a maneira como estes foram apresentados ao público argentino, com especial destaque à figura do romancista brasileiro Franklin Távora. Nesta perspectiva, entendemos que as instâncias de mediação cultural são "produtoras de discursos e estratégias que prescrevem práticas de apropriação, legitimam ou não repertórios e franqueiam caminhos para a difusão social de determinados conteúdos culturais". (SOARES, 2011, p. 91)

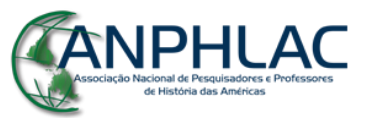

Revista Eletrônica da ANPHLAC, ISSN 1679-1061, №. 21, p. 209-231, Jul./Dez., 2016.

http://revista.anphlac.org.br 
Trabalhos recentes têm chamado a atenção para os mecanismos de recepção ${ }^{2}$ que, embora de difícil sistematização, possibilitam algumas inferências sobre o significado atribuído aos suportes materiais:

Em busca de saídas para a escassez de fontes que recuperem as formas subjetivas de recepção das ideias em circulação, alguns autores sublinharam o esforço de determinados mediadores para construir comunidades interpretativas, estabelecendo maneiras de "ler" e apropriações autorizadas, com vistas a conformar horizontes culturais. (SOARES, 2011, p. 93)

A Nueva Revista de Buenos Aires estava comprometida com um grupo específico da sociedade argentina, composto por uma elite sociocultural, e expressava suas inquietudes ante a modernização do país. Estas inquietudes estiveram associadas a um programa de construção da nacionalidade que devia apelar aos valores da cultura estética para resultar exitosa (TERÁN, 2000, p. 25). Havia na Argentina dos anos 1880 um sentimento fóbico ante a perda da deferência, uma sensação de cerceamento da elite, permeado por um olhar severo às modificações estruturais introduzidas pela imigração massiva. Diante deste cenário, os editores do periódico argentino atuaram no sentido de fortalecer uma determinada configuração interna do país ao mesmo tempo em que o projetava culturalmente além fronteiras.

\section{A gênese de uma ideia}

Vicente Gregório Quesada iniciou sua carreira pública em 1852, a convite de Juan Pujol, governador de Corrientes, e foi alçado a deputado nacional pela mesma província no ano de 1856, quando tinha apenas vinte e cinco anos. Portenho de nascimento, Quesada exerceu funções políticas no governo da Confederação Argentina ${ }^{3}$ sediada na cidade de Paraná, província de Entre Rios, onde também desenvolveu seu primeiro projeto cultural, com a fundação da Revista de Paraná, em 1861. A revista não resistiu à crise da Confederação, mas

\footnotetext{
${ }^{2}$ Ver CHARTIER, 1992; DARNTON, 1998; DAVIDSON, 1989.

${ }^{3}$ Após a Batalha de Caseros em 1852 e da consequente queda do governo de Juan Manuel de Rosas, teve início a Confederação Argentina. Justo José Urquiza, vitorioso sobre Rosas, propôs a rediscussão de pontos de divergência entre Buenos Aires e as províncias do interior do país, que culminou com a promulgação da Constituição de 1853. Buenos Aires, porém, não reconheceu a legitimidade de Urquiza e da Constituição nacional e manteve-se como um Estado autônomo. Esta situação perdurou até o ano de 1861, quando, após a Batalha de Pavón, comandada pelo general Bartolomé Mitre, ocorreu a reunificação do país sob a égide de Buenos Aires.
}

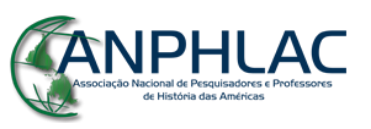

Revista Eletrônica da ANPHLAC, ISSN 1679-1061, №. 21, p. 209-231, Jul./Dez., 2016.

http://revista.anphlac.org.br 
proporcionou a participação de Quesada em um extenso e articulado espaço de intercâmbio de livros, papeis e documentos pertencentes a escritores e letrados latino-americanos. Naquela conjuntura, Quesada estabeleceu estreito vínculo com Gregorio Béeche, por exemplo, um dos bibliófilos mais conhecidos e influentes dos círculos culturais sul-americanos. (BUCHBINDER, 2012, p. 83)

Após a batalha de Pavón, Quesada se viu marginalizado politicamente, vítima da campanha contra os chamados alquilones, como eram chamados os políticos portenhos que haviam trabalhado nos governos provinciais da Confederação. Assim, de volta à sua cidade natal, dedicou-se à carreira jurídica e às atividades culturais. Em abril de 1863, deu inicio a um novo empreendimento jornalístico com a publicação do primeiro número da Revista de Buenos Aires, dirigida conjuntamente com Miguel Navarro Viola, e que contou com a colaboração de figuras destacadas do âmbito político argentino e latino-americano, tais como Diego Barros Arana, Ángel Justiniano Carranza, Manuel Trelles, Juan M. Gutiérrez, Juana Manuela Gorriti, Bartolomé Mitre, entre outros. Paul Groussac, importante escritor e erudito franco-argentino, afirmou que a revista constituía-se na melhor iniciativa, até aquele momento, de aclimatar uma forma de publicação mista que se aproximava do livro, por sua matéria, e do diário, por sua atualidade. (BUCHBINDER, 2012, p. 85-86)

A Revista de Buenos Aires dava continuidade ao intuito, esboçado no empreendimento anterior de Quesada, de congregar as províncias argentinas, visando a superação dos conflitos políticos que afligiam a jovem República. De acordo com Nicolas Schumway, as divergências de interesses entre Buenos Aires e as províncias do interior mudaram de nome ao longo do século XIX ${ }^{4}$, mas mantiveram uma qualidade de déjà vu pronunciada. (SHUMWAY, 2008, p.78) Assim, constituiu-se uma linha divisória no país que, em certo sentido, originou uma mitologia de exclusão em lugar de um ideal nacional unificador, uma receita para a cisão em vez de um pluralismo de consenso.

Esse fracasso em criar um quadro ideológico unificador ajudou a produzir o que o novelista Ernesto Sábato chamou de "sociedade de opositores", tão interessada em humilhar o outro como em desenvolver uma nação viável pelo acordo e consenso. (SHUMWAY, 2008, p.17)

\footnotetext{
${ }^{4} \mathrm{O}$ autor apresenta como exemplos as oposições entre "morenistas" versus "saavedristas"; unitários versus federalistas; nacionalistas versus liberais.
}

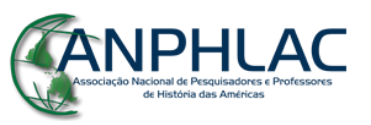

Revista Eletrônica da ANPHLAC, ISSN 1679-1061, №. 21, p. 209-231, Jul./Dez., 2016.

http://revista.anphlac.org.br 
Ambas as publicações de Quesada se colocavam na contracorrente desta tendência. A novidade do novo empreendimento foi a ênfase dada aos países americanos, com o objetivo de rechaçar o estigma de inferioridade cultural, reivindicar os antecedentes literários do continente frente aos críticos do Velho Mundo e exaltar a originalidade latino-americana por meio de suas expressões culturais e literárias. O campo das ideias era considerado por Vicente Quesada como um terreno neutro para se criar vínculos de solidariedade e amizade entre países e povos. Considerava, assim, a cooperação intelectual um âmbito propício para que estes pudessem se conhecer, conviver e construir uma pacífica coexistência entre as nações. (BUCHBINDER, 2012, p. 85)

A revista deixou de circular em 1871, devido a dificuldades financeiras e a nomeação de Vicente Quesada como diretor da Biblioteca Pública da Província de Buenos Aires. De acordo com Buchbinder, é provável que a fama obtida por Quesada na direção da Revista de Buenos Aires e seu já conhecido empenho em formar grandes coleções de livros sobre temas americanos tenham pesado em sua nomeação pelas autoridades governamentais (BUCHBINDER, 2012, p. 89). Durante seus primeiros anos à frente da instituição, a construção de uma rede de intercâmbio de publicações foi, provavelmente, sua maior preocupação. Com esse objetivo, procurou comprometer os representantes e embaixadores argentinos na Europa, América Latina e Estados Unidos.

A nova função levou Quesada a uma viagem pela Europa com o objetivo de estudar a organização das principais bibliotecas daquele continente e realizar pesquisas em arquivos espanhóis. Ernesto Quesada acompanhou seu pai em uma parte desta viagem, pois permaneceu em Dresden, Alemanha, por mais de um ano para aprender alemão e aprimorar seus estudos. De volta à Argentina, Vicente Quesada foi nomeado Ministro do Governo da Província de Buenos Aires, posteriormente eleito deputado nacional pela mesma província e presidente da Academia de Filosofia e Letras da Universidade de Buenos Aires. (RAMÍREZ BRASCHI, 2004, p. 02)

Ao final do século XIX, as revistas consistiam um meio, em particular para seus editores, para a construção de redes intelectuais. As publicações periódicas eram úteis para estreitar laços sobre os quais circulavam informações, livros e ideias e a fundação da Nueva

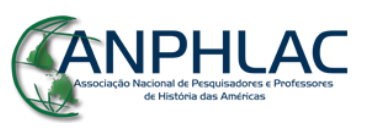


Revista de Buenos Aires, em 1881, por Vicente e Ernesto Quesada, confluiu para a esse propósito.

No início da década de 1880, Ernesto Quesada, com pouco mais de 20 anos, dividia-se entre os estudos de direito na Universidade de Buenos Aires, a docência no ensino secundário, a direção da Nueva Revista de Buenos Aires e uma intensa vida social. Entre os locais de sociabilidade frequentados por Ernesto Quesada destacavam-se os bailes de verão nas estâncias, oferecidos por personalidades relevantes da sociedade portenha, ocasiões nas quais mantinha contato com as famílias Coronado, Obligado, Urigarte, Alvear, Ocantos, entre outros; o Clube do Progresso, instituição relativamente fechada que promovia severas exigências para a aceitação de membros e na qual seu ingresso foi uma extensão das redes de relações iniciadas nos bailes de verão; a cidade de Montevidéu, para onde Ernesto Quesada se dirigia para obter relações sociais e literárias, bem como colaboradores para a revista; e a Universidade de Buenos Aires, na qual se graduou advogado em 1882, integrando uma geração de figuras que se tornaram centrais na vida cultural e política argentina em princípios do século XX, como Juan Agustín García, Rodolfo Rivarola e Nicolás Matienzo, os quais também assinaram textos na Nueva Revista de Buenos Aires.

Da virada do século XIX ao Centenário da Independência, Ernesto Quesada participou ativamente dos debates acerca da identidade nacional, constituindo-se em um dos porta-vozes de grupos nacionalistas que defendiam a tradição federalista, o idioma nacional, a vinculação do país à Madre Pátria, a solidariedade latino-americana em contraposição às pretensões estadunidenses e, com base nestes pilares, a conformação de uma cultura que se pretendia de fato nacional (BERTONI, 2001). Os elementos que comporiam o discurso nacionalista de Quesada apresentaram seus primeiros contornos nas páginas da Nueva Revista de Buenos Aires, que tinha como cerne de seu programa a missão patriótica de desenvolver e fomentar a cultura argentina e suas conexões com a América Latina.

Ao final do século XIX, Buenos Aires assistiu ao surgimento de vários periódicos ${ }^{5}$ que se tornaram porta-vozes de grupos políticos e intelectuais que aspiravam exercer influência na sociedade. De acordo com Hilda Sabato:

\footnotetext{
${ }^{5}$ Naquela conjuntura, Buenos Aires contava com uma das maiores circulações de periódicos a nível mundial, impulsionada pelas políticas de alfabetização implementadas desde a década de 1860. Cf. ALONSO, 1997, p. 38.
}

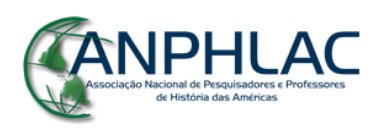


La prensa constituía una pieza clave del sistema político. Por un lado, se la consideraba un instrumento fundamental para el desarrollo de las formas republicanas y la creación de una sociedad racional e ilustrada. A ella correspondía representar a la vez que forjar a la opinión pública, pilar del sistema político moderno. (SÁBATO, 1999, p. 195)

Buscava-se, assim, a conformação de uma esfera pública, acepção proposta pelo filósofo alemão Jürgen Habermas ${ }^{6}$ e entendida como um conjunto de grupos privados reunidos a fim de discutir em âmbito público interesses específicos, atuando como intermediários entre a sociedade civil e o Estado. (HABERMAS, 1984, p. 42) De acordo com Habermas, a esfera pública constituiu-se no princípio organizacional do ordenamento político moderno, cujo componente base era a opinião pública. A imprensa apresentava-se como órgão vital da esfera pública na medida em que expressava os posicionamentos dos setores sociais (HABERMAS, 1984, p. 14-17). Neste contexto, as revistas, estreitamente ligadas aos espaços e redes de sociabilidade, tornaram-se um fenômeno-chave. As iniciativas culturais de Vicente Quesada revelavam o intento de criar instituições, redes de sociabilidade cultural e construir um espaço de projeção social à margem da política militante, que não obstante lhe possibilitasse intervir nesta esfera pública argentina. Buscava, por meio desses empreendimentos, assegurar a autonomia dos processos de construção cultural, afirmar uma autoridade e um lugar de enunciação e consolidar uma posição como escritor, letrado e como organizador cultural.

\section{A Nueva Revista de Buenos Aires: um dispositivo para conformação da cultura argentina e latino-americana.}

A Nueva Revista de Buenos Aires era entendida por seus proprietários como um dispositivo para a conformação da cultura argentina e latino-americana na medida em que tudo que era considerado importante no universo letrado do continente deveria passar pelo crivo do periódico. Nesse sentido, Vicente e Ernesto Quesada atuaram como correlatos da figura do "protetor cultural", característico de um primeiro estágio de formação do mercado editorial argentino:

\footnotetext{
${ }^{6}$ Cf. HABERMAS, 1984. A tradução do termo Öffentlichkeit para as línguas latinas foi objeto de controvérsias, oscilando entre as noções de esfera pública e de espaço público.
} 
El género propio del protetor cultural fue la crítica, en tanto permitía cumplir su misión de guía y estímulo. Esa misión fue un signo y un deber de clase: un signo de nobleza y un "nobleza obliga". Debía estimular simbólicamente, ante la insuficiencia de estímulos materiales, el desarrollo de la cultura nacional, pero también orientar ese desarollo ejerciendo las funciones de un árbitro del gusto. (PASTORMERLO, 2014, p. 20)

Em mais de uma ocasião, os proprietários externaram as dificuldades quanto à manutenção da revista devido à escassez de assinantes e a proposta de não publicar anúncios publicitários. Todavia, deixavam claro que a "esta no es empresa de lucro, sino de propaganda; una vez cubierto el costo material, el excedente sirve solo para fomentar la marcha del periódico. Se trata de una cuestión de patriotismo y no de provecho pecuniario". (QUESADA, 1884, p. 03)

O programa da revista buscava a delimitação de uma cultura literária que se pretendia de fato nacional por englobar todas as províncias argentinas e que se espraiava na busca pelo fomento das letras latino-americanas cuja singularidade e originalidade deveriam ser conhecidas por todos. O primeiro objetivo trazia consigo a reflexão acerca dos conflitos entre Buenos Aires e as províncias do interior que incidiam, de acordo com a revista, nas políticas culturais do país. Questionava-se, por exemplo, o desconhecimento acerca de tudo que era produzido fora de Buenos Aires. O segundo aspecto, acenava para uma perspectiva de solidariedade latino-americana pouco pronunciada no século XIX e que colocou a revista como um pioneiro no tocante aos intercâmbios culturais no continente. ${ }^{7}$

Destacamos, porém, que a Nueva Revista de Buenos Aires dirigia-se a um "público delicado e instruído" (RACOT, 1884, p. 129) e postava-se como representante da cultura erudita argentina. Assim, não houve sequer uma menção à literatura criolla ${ }^{8}$ no periódico. A omissão do êxito de El gaucho Martin Fierro, de José Hernández, que vendeu 48.000 cópias entre 1872 e 1878 e das primeiras novelas de Eduardo Gutierrez são significativas quanto ao lugar social ocupado pela Nueva Revista de Buenos Aires e seus editores que buscavam definir uma política cultural alinhada a uma certa concepção de Estado Nacional, na qual esta literatura popular,

\footnotetext{
${ }^{7}$ Ernesto Quesada salientava que a Nueva Revista de Buenos Aires tinha por objetivo promover as letras não só das nações americanas de origem espanhola, mas de todas de procedência latina. $C f$. QUESADA, 1884, p. 05.

${ }^{8}$ Publicada em forma de folhetim nos periódicos ou em papel de baixa qualidade com custos reduzidos, a literatura criollista ou gauchesca era uma expressão da cultura popular, escrita e difundida em grande medida após 1880 . $C f$. PRIETO, 1988, p. 97.
}

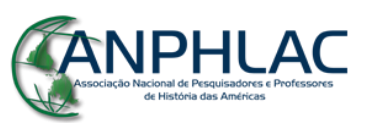

Revista Eletrônica da ANPHLAC, ISSN 1679-1061, №. 21, p. 209-231, Jul./Dez., 2016.

http://revista.anphlac.org.br 
cujo objetivo era entreter e propor um passatempo ao contingente de leitores situados na base da pirâmide social, não se enquadrava.

Com uma periodicidade mensal, a Nueva Revista de Buenos Aires contava em média com 160 páginas $^{9}$ divididas, a princípio, entre assuntos americanos, sob a direção de Vicente Quesada, e europeus, aos cuidados de Ernesto Quesada ${ }^{10}$. Estas eram subdivididas em seções que tratavam de política e cultura literária. No prefácio do primeiro volume, porém, afirmavase que a história americana se constituiria na especialidade da Nueva Revista, sendo a "parte europeia" um contraponto para que os leitores pudessem apreciar os avanços argentinos, e latino-americanos em geral, em comparação com os que se realizavam no velho continente. (QUESADA, 1881, p. 06)

Os diretores se mostravam preocupados com o "isolamento cultural" que persistia na Argentina e que distanciava Buenos Aires das províncias do interior, bem como o distanciamento em relação aos países latino-americanos. Desse modo, empenhavam-se em dar a conhecer as obras dos mais diversificados autores. Ao longo dos anos, a revista dedicou cada vez mais espaço à produção cultural e à crítica literária, com um maior volume de artigos inéditos de inúmeros colaboradores, resenhas de livros e reflexões acerca da vida intelectual no continente. Além de suprimir a seção europeia, "para fazer da Nueva Revista uma publicação exclusivamente americana, em cujas páginas se publicam trabalhos escritos sobre a América ou por americanos". (QUESADA, 1884, p. 06) Tais mudanças estiveram relacionadas à presença de Ernesto Quesada à frente do periódico que, quando do início da carreira diplomática de seu pai, em 1883, assumiu a função de único diretor.

De acordo com Ernesto Quesada, o mensário cumpriu função similar à da Revue des deux Mondes, na França, da Deutsche Rundschau, na Alemanha, Nuova Antologia, na Itália, Atheneum e Nineteenth Century, na Inglaterra. (QUESADA, 1884, p. 10) A revista francesa teve ampla circulação e foi um importante canal de transferências culturais entre a Europa e a

\footnotetext{
${ }^{9}$ Posteriormente, a revista era editada em tomos, compostos por quatro volumes, pela Imprenta e Librería de Mayo, de propriedade de Carlos Casavalle. A partir do décimo tomo, em abril de 1884, a revista passou a circular por meio de impressão própria.

${ }^{10}$ Neste artigo, enfatizamos a atuação dos editores no âmbito das transferências culturais americanas, embora seja importante a reflexão sobre o papel de Ernesto Quesada enquanto mediador cultural entre a Europa e a América Latina, levada a cabo por meio da seleção dos temas e discussões publicadas pela Nueva Revista de Buenos Aires na seção europeia.
}

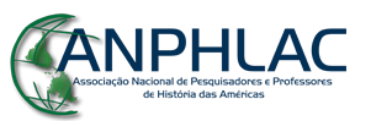

Revista Eletrônica da ANPHLAC, ISSN 1679-1061, №. 21, p. 209-231, Jul./Dez., 2016.

http://revista.anphlac.org.br 
América Latina ao longo do século XIX, propondo-se uma intermediária cultural, cujo objetivo era transportar elementos de uma cultura para outra e de aproximá-las. (CAMARGO, 2007, p. 29) Por meio da apropriação de um modelo de publicação europeu, que pode ser observado pelas similaridades da capa e dos objetivos, Vicente e Ernesto Quesada idealizaram a Nueva Revista de Buenos Aires como uma ferramenta de mediação cultural no contexto latinoamericano. Mais do que isso, destacamos que neste processo de ressignificação, o periódico argentino questionou declarações da Revue des deux Mondes, demarcando o lugar da Argentina e da América Latina frente a uma visão eurocêntrica.

Em artigo publicado no Tomo V, a Nueva Revista de Buenos Aires replicou a afirmação de um correspondente da Revue des deux Mondes sobre a inviabilidade da manutenção de revistas literárias na Argentina devido à falta de literatos. Em resposta, o autor argentino salientou a qualidade dos homens de letras do país e a originalidade cultural latino-americana, embora reconhecesse as dificuldades decorrentes da não profissionalização dos intelectuais e dos parcos ganhos destes com as atividades literárias. Por este motivo, a revista defendia ardorosamente a criação de uma lei de propriedade intelectual. (E. O. A., 1882, p. 454-461)

Com vistas à aproximação cultural no continente, Vicente e Ernesto Quesada se empenhavam para arregimentar colaboradores, compostos por ilustres políticos e intelectuais, em diversos países latino-americanos. Além de autores argentinos, assinaram artigos na Nueva Revista de Buenos Aires os peruanos José Antonio Lavalle, Mariano Felipe Paz Soldán, Cesáreo Chacaltana e Pedro Paz Soldán y Unánue; os colombianos Francisco Javier Balmaceda, José M. Samper, Salvador Camacho Roldan e Adriano Páez; os bolivianos Gabriel René-Moreno, Santiago Vaca Guzman e Modesto Omiste Tinajeros; os mexicanos Victoriano Agueros, Ignacio M. Altamirano, Juan Dios Peza e Gómez Flores; os chilenos Miguel Luis Amunátegui, Santiago Escuti Orrego; o nicaraguense, radicado em El Salvador, Mayorga Rivas; os uruguaios Andrés Lamas e Juan Zorrila de San Martín; os brasileiros Franklin Távora, Silvio Romero e Santa Anna Nery, entre outros.

Os textos redigidos por estrangeiros que estamparam as páginas da Nueva Revista de Buenos Aires foram viabilizados pela extensa rede de sociabilidade latino-americana tecida por Vicente e Ernesto Quesada, uma vez que as colaborações eram voluntárias e não obedeciam uma regularidade. Para a expansão dos objetivos do periódico, Ernesto Quesada considerava

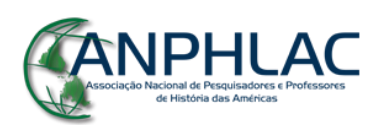


imprescindível o aperfeiçoamento deste cenário, a fim de regularizar a colaboração nacional e estrangeira, fazendo-as elucidar todas as questões que preocupassem a opinião pública dentro e fora do país. Para lograr isso, afirmava ele, só havia uma maneira: remunerar pecuniariamente os autores e converter a colaboração em um trabalho metódico e seguro. Isso equivalia permitir a muitos escritores ganhar a vida com sua pluma e daria início à profissionalização dos homens de letras na América. (QUESADA, 1884, p. 09-10)

Além dos artigos originais, a Nueva Revista de Buenos Aires publicava resenhas críticas de obras de autores nacionais e estrangeiros inseridas na seção Revista Bibliográfica. Os diretores da revista solicitavam aos autores, editores ou livreiros interessados nesta publicidade que enviassem um exemplar de suas publicações, se desejassem uma simples menção e dois exemplares para a realização de um juízo crítico, proporcional à importância da obra. Outra característica era a utilização de transcrições retiradas de periódicos latino-americanos.

O mensário propôs que as revistas latino-americanas que quisessem estabelecer intercâmbio deveriam entrar em contato, a fim de regularizar o serviço, pois a Nueva Revista oferecia hospitalidade aos escritores americanos que se interessassem em divulgar o movimento intelectual de seus países, propósito que convergia com o objetivo de estreitar os laços que uniam as nações do continente. Assim, se as direções de outros periódicos americanos desejassem, poderiam estabelecer reciprocidade desse serviço.

A Nueva Revista de Buenos Aires buscava ampliar um diálogo já existente com instituições culturais do continente. Em seu quinto volume, em agosto de 1881, o mensário anunciava que havia começado a receber publicações das "repúblicas hermanas" da América Latina:

De San Salvador ha recibido la notable revista La Juventud, y el interesante semanario La Linterna; mientras que de Colombia, si bien aún no ha llegado el académico Repertorio Colombiano y la importante Patria de Paez, tiene ya los semanarios El Pasatiempo y La Caridad, debiendo anunciar com sentimiento que la curiosa revista La Mujer que dirige la afamada escritora Soledad Acosta Samper, acaba de desaparecer. (Revista bibliográfica, 1881, p. 203)

Os intercâmbios culturais operacionalizados por Vicente e Ernesto Quesada por meio da Nueva Revista de Buenos Aires e ampliados no decorrer dos anos levaram ao público

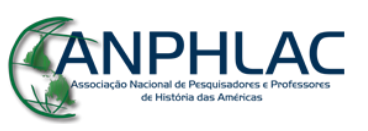


argentino poemas e crônicas assinadas por autores latino-americanos, bem como artigos críticos sobre o movimento intelectual na Colômbia, México, Bolívia, Chile e Brasil.

\section{Franklin Távora: um elo entre o Brasil e a Argentina.}

Um dos mais assíduos colaboradores estrangeiros da Nueva Revista de Buenos Aires foi o romancista, jornalista, advogado e político brasileiro Franklin Távora. Cearense de nascimento, Távora iniciou sua carreira literária em $1861^{11}$, em Recife, Pernambuco, enquanto estudante da Faculdade de Direito. Como era característico dos literatos no século XIX, Távora conciliava suas incursões culturais com as mais variadas ocupações. Diante das dificuldades financeiras da família, sobretudo após a morte de seu pai, e dos parcos rendimentos com a advocacia, Távora trabalhou como revisor e redator em jornais e alçou-se deputado provincial no biênio 1867-1868, com apenas 25 anos de idade, desempenhando inclusive a função de Diretor Geral da Instrução Pública.

Tanto em sua curta atividade política, quanto em suas obras literárias, Franklin Távora posicionou-se no sentido de deixar de lado

um certo deslumbramento pelas coisas oriundas da velha Europa, sobretudo as da França. Devíamos, bradava o então deputado provincial, nos preocupar mais com as (coisas) americanas, as nacionais ou as regionais, aspectos que melhor se afinavam com as preocupações. (AGUIAR, 1997, p. 178)

Este pressuposto marcou de maneira decisiva a carreira do escritor, voltada para um regionalismo que "fixasse as cores e os costumes da terra" e para a constituição de "uma literatura mais coerente e viva". (AGUIAR, 1997, p. 179)

Em 1874, Franklin Távora mudou-se para o Rio de Janeiro, onde se empregou como oficial de gabinete na Secretaria do Império. Embora o cargo fosse essencial ao sustento da família, era considerado pelo romancista um empecilho à realização de suas atividades culturais. Em carta ao amigo escritor José Veríssimo, em 11 de novembro de 1880, Távora

\footnotetext{
${ }^{11}$ Entre as obras de Franklin Távora destacamos Trindade Maldita (1861); Os índios do Jaguaribe (1862); Um casamento de Arrabalde (1869); O Cabeleira (1876); O Matuto (1878); Lendas e Tradições do Norte (1878), além de inúmeros textos jornalísticos e críticas literárias.
}

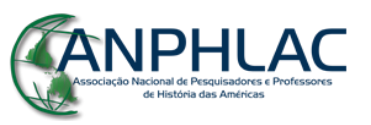

Revista Eletrônica da ANPHLAC, ISSN 1679-1061, №. 21, p. 209-231, Jul./Dez., 2016.

http://revista.anphlac.org.br 
parabenizou o destinatário por um discurso sobre a propriedade intelectual realizado no Congresso Literário Internacional, sediado em Lisboa, no mesmo ano. Ressaltou o patriotismo e compreensão de Veríssimo sobre as "coisas literárias" do Brasil ${ }^{12}$ ao tratar deste tema fundamental que incidia na possibilidade dos homens de letras poderem viver de seus escritos.

A defesa de uma lei que garantisse a propriedade intelectual foi um tema caro à Nueva Revista de Buenos Aires e alvo de diversos textos. Assim, o referido discurso de José Veríssimo também repercutiu entre os diretores do periódico argentino. Em nota a um artigo transcrito sobre a literatura brasileira, os Quesada salientaram que o literato brasileiro

\begin{abstract}
señor José Veríssimo, lo explicaba en el Congreso literario de Lisboa, adoléce en el Brasil del mismo defecto que en Rio de la Plata - con raras excepciones no hay editores, es decir, libreros que compren los manuscritos á los autores, ó aun que los impriman gratis. Los que tanto allí como aquí se adornan con el pomposo nombre de editores - repito que hay excepciones - son meros impresores, pues el autor paga de su proprio bolsillo el costo de su libro (...) Resulta de esto que la literatura es un verdadero lujo en las naciones latino-americanas, porque de su pluma no vive en estos países escritor alguno, si se exceptúa á los diaristas ó polemistas y panfletistas en materia política. El hecho es triste, pero es exacto. (N. de la Direc. ROMERO, 1882, p. 485)
\end{abstract}

Passados os primeiros meses de adaptação no Rio de Janeiro, Távora fez amigos e aproximou-se de pessoas ligadas à imprensa e à vida literária carioca. Em 1875, recebeu o convite de Henrique Fleiuss para trabalhar na revista Ilustração Brasileira (1876-1878). A ele coube a responsabilidade de resenhar livros e de cuidar de assuntos literários (AGUIAR, 1997, p. 221). A partir de 1879, Távora participou da reestruturação e direção da Revista Brasileira, publicação que propunha "representar a literatura brasileira, independente e, quanto possível, viva"13. $^{13}$.

Fundada em 1857, a Revista Brasileira encontra-se atualmente em sua sétima fase, aos cuidados da Academia Brasileira de Letras. Sua segunda fase, de maio de 1879 a dezembro de 1881, foi capitaneada por Nicolau Midosi, Franklin Távora, Balduíno Coelho, Cândido Rosa e Moreira Sampaio, todos funcionários da Secretaria do Império. Em suas páginas tiveram primeira publicação as Memórias Póstumas de Brás Cubas, de Machado de Assis, os poemas

\footnotetext{
${ }^{12}$ Franklin Távora. Carta a José Veríssimo, datada do Rio de Janeiro, em 11 de novembro de 1880. $C f$. Arquivo da Academia Brasileira de Letras (Pasta 27-1-18).

${ }^{13}$ Franklin Távora. Carta a José Veríssimo, datada do Rio de Janeiro, em 19 de julho de 1881. Cf. Arquivo da Academia Brasileira de Letras (Pasta 27-1-18).
}

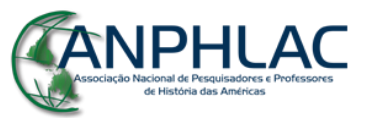


de Fagundes Varela que constituíram $O$ Diário de Lázaro, a "Introdução da literatura brasileira", de Sílvio Romero, aproveitada mais tarde na sua História da Literatura brasileira, entre tantas e importantes colaborações. ${ }^{14}$

\begin{abstract}
A Revista Brasileira se constituiu em um importante suporte material mobilizado por Vicente e Ernesto Quesada com o objetivo de aproximar culturalmente Brasil e Argentina. Os diretores afirmaram que aquela publicação havia logrado constituir "un centro al que converjen todas las inteligencias brillantes con que cuenta el Brasil, registrando en suas páginas produciones de las mas diversa naturaleza, desde la abstracta filologia hasta la fascinadora novela". (N. de la Direc. ROMERO, 1882. p. 484)
\end{abstract}

O primeiro artigo transcrito da Revista Brasileira no periódico argentino foi assinado por Silvio Romero, no qual o autor fazia um balanço sobre a literatura nacional contemporânea. (ROMERO, 1882, p. 483-507) Os editores argentinos justificaram a publicação afirmando que se ocupar com o "grande imperio, vecino y amigo" confluía com o programa da Nueva Revista e com

el ardiente deseo que la anima de estrechar los lazos de confraternidad entre las naciones de América Latina, publicando estudios sobre la vida intelectual de sus distintos pueblos, para facilitar el conocimiento mutuo de sus literaturas y para que puedan ejercer recíprocamente la legítima influencia que les corresponde. ( $N$. de la Direc. ROMERO, 1882, p. 483)

Por meio deste expediente, outros autores brasileiros figuraram nas páginas da publicação argentina, como por exemplo, Silvio Dinarte, pseudônimo de Alfredo A. d'Escragnolle Taunay e o próprio Franklin Távora.

Com uma defasagem temporal, característica da circulação de impressos no século XIX, a Nueva Revista de Buenos Aires lamentou o encerramento das atividades do periódico brasileiro em dois artigos publicados no tomo V no ano de 1882: Las Revistas en América Revista Brazileira - Revista de Chile - Los literatos en la República Argentina (E.O.A., 1882, p. $454-461)^{15}$ e El movimiento intelectual argentino: revistas e periódicos (QUESADA, 1882,

\footnotetext{
${ }^{14} C f$. <http://www.academia.org.br/publicacoes/revista-brasileira> Acesso em 09/12/2015.

${ }^{15}$ Via de regra, os textos publicados pela Nueva Revista de Buenos Aires eram assinados. Este artigo, porém, foi subscrito apenas pelas iniciais E. O. A., não sendo possível assegurar sua autoria. Devido a seu conteúdo, é possível afirmar que o autor estava bastante familiarizado com a dinâmica da revista, bem como com os detalhes do empreendimento anteriormente dirigido por Vicente Quesada, a Revista de Buenos Aires.
}

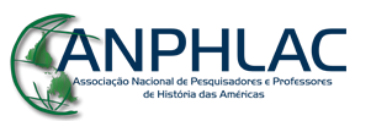

Revista Eletrônica da ANPHLAC, ISSN 1679-1061, №. 21, p. 209-231, Jul./Dez., 2016.

http://revista.anphlac.org.br 
p. 462-475). De maneira geral, ambos os artigos discorreram acerca das dificuldades que pairavam sobre os projetos dessa natureza devido à falta de assinantes, editores, apoio governamental e de patriotismo da população. Neste ensejo, ressaltou-se a importância da constituição de uma literatura nacional, da busca pela consolidação de um mercado editorial latino-americano, que acarretasse no fortalecimento e na projeção das produções literárias do continente e defendeu novamente a elaboração de uma lei que garantisse a propriedade intelectual. (E.O.A., 1882, p. 454-461)

De acordo com Ernesto Quesada, em decorrência destas dificuldades, a América Latina vivia em um isolamento cultural inadmissível e só fortuitamente era possível conhecer as publicações dos países vizinhos. $\mathrm{O}$ autor lamentou o fato de serem poucos os privilegiados que conheciam a Revista del Plata e os Anales del Ateneo, de Montevidéu, a Revista Paraguaya, de Assunção, La Patria e o Repertório Colombiano, de Bogotá, a Revista Literaria, de Quito, La Juventud, de San Salvador, a Revista Mexicana, do México e a Revista Literaria, de Havana, bem como a Revista Brasileira e a Revista de Chile, que sucumbiram na tentativa de aclimatar esse tipo de empreendimento no continente. (QUESADA, 1882, p. 474) Ao final do artigo, Quesada reiterou o compromisso patriótico da Nueva Revista de Buenos Aires no sentido de estreitar os vínculos de solidariedade nacional, criar uma verdadeira vida intelectual em toda a República e fazer cessar o "isolamento pernicioso" a respeito das nações latino-americanas. De acordo com ele, a tarefa era árdua e para que se concretizasse, era preciso que as poucas revistas existentes unissem seus esforços e prestassem apoio mútuo. (QUESADA, 1882, p. 475)

O fim da Revista Brasileira, contudo, significou um novo relacionamento entre Franklin Távora e Nueva Revista de Buenos Aires. A partir de então, o brasileiro iniciou uma série de artigos sobre a "literatura nortista", escritos expressamente para o mensário argentino.

Távora criticava o desinteresse dos escritores da Corte Imperial pelo que se passava nas províncias e tinha como um de seus principais projetos a publicação de uma coletânea que se intitularia $O$ Norte, uma interpretação crítica e biográfica que conteria as principais obras de vinte escritores considerados bons exemplos do talento nortista ${ }^{16}$. Os fundamentos que justificariam a existência de uma literatura do Norte, de acordo com Távora, era "um certo

\footnotetext{
${ }^{16} \mathrm{Na}$ concepção do autor, o termo Norte referia-se a uma diferenciação mais geral entre Norte e Sul do país, abrangendo genericamente o que hoje se entende pelas regiões norte e nordeste.
}

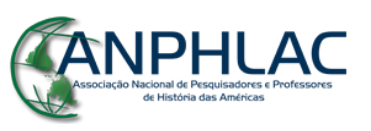

Revista Eletrônica da ANPHLAC, ISSN 1679-1061, №. 21, p. 209-231, Jul./Dez., 2016.

http://revista.anphlac.org.br 
caráter geográfico para as letras, a feição primitiva, pureza e a genuína expressão do Norte, ainda não afetada pela invasão dos imigrantes estrangeiros como se dava no Sul". (AGUIAR, 1997, p. 250-251)

O romancista brasileiro sustentava a convicção - cultivada desde 1874, quando transladou-se de Recife para o Rio de Janeiro - de que existia no Brasil duas escolas literárias, visíveis nas produções das duas grandes regiões em que se dividia naturalmente o país, separadas pelo Rio São Francisco. De acordo com Távora, leis do meio físico, a natureza e o clima provocavam diferenças que modificavam o homem e influíam forçosamente na formação de sua individualidade, incidindo também nas produções literárias. (TÁVORA, 1882, p. 224225)

Os trabalhos de Távora eram expressões do naturalismo literário brasileiro. De acordo com Nicolau Sevcenko (2003, p. 275-276), o realismo e o naturalismo representavam a sociedade multifragmentada brasileira do final do século XIX, na qual, havendo sido rompido o sistema de hegemonia de uma elite uniforme, vários grupos sociais se viam encorajados a conceber a sociedade a partir de sua perspectiva particular. Contudo, a despeito da divisão apresentada, Távora acreditava que seus estudos sobre os escritores do norte do Brasil contribuiriam para o fortalecimento da literatura nacional e fazia votos de que suas reflexões despertassem interesse nos leitores argentinos e brasileiros.

O objetivo de Franklin Távora com estes artigos era apresentar escritores das províncias, contemporâneos, mas desconhecidos na capital do Império. De acordo com ele, o mais lamentável desta conjunção era o fato dos escritores da Corte - aqueles que deviam conhecer o movimento literário do país -, guardarem silêncio acerca dos colegas provenientes das demais províncias, promovendo um verdadeiro atentado contra a literatura nacional e a pátria, em uma demonstração do egoísmo de metrópole. (TÁ VORA, 1882, p. 222)

O projeto de compilação da obra $O$ Norte não se realizou em sua totalidade. ${ }^{17}$ Entretanto, oito artigos inéditos foram publicados pela Nueva Revista de Buenos Aires entre os

\footnotetext{
${ }^{17}$ Parte substancial deste livro, dado como perdido, foi recuperada pelo biógrafo Cláudio Aguiar a partir de publicações originais traduzidas para o espanhol por Ernesto Quesada na Nueva Revista de Buenos Aires entre os anos de 1882-1883, bem como outros capítulos publicados esparsamente em jornais, revistas ou livros no Brasil. Os originais de $O$ Norte, juntamente com outros trabalhos inéditos, segundo informações de Sílvio Romero, que foi amigo do romancista, Távora os "pôs no fogo num momento de desespero, quando, pouco antes de sua morte..." em 1888. Cf. AGUIAR, 1997, p. 260.
}

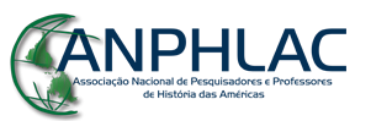

Revista Eletrônica da ANPHLAC, ISSN 1679-1061, №. 21, p. 209-231, Jul./Dez., 2016.

http://revista.anphlac.org.br 
anos de 1882 e 1884. A série intitulada Escritores del norte del Brasil levou ao público argentino e latino-americano ensaios sobre a vida e obra de Luis Dolzami - pseudônimo de Inglês de Sousa -, Carlos Hipólito de Santa Helena Magno, Julio Cesar Ribeiro de Souza, José Veríssimo, José Coriolano de Souza Lima, Juvenal Galeno, Thomaz Antonio Ramos Zanny e de José de Barcellos.

A Nueva Revista de Buenos Aires se tornou um veículo importante para a divulgação dos trabalhos de Franklin Távora. Em carta a José Veríssimo, Távora falou sobre sua vinculação com a Nueva Revista de Buenos Aires e a publicação dos artigos relacionados sobre os escritores do Norte:

\begin{abstract}
Se porém a impressão em volume especial está por ora sem andamento, uma das duas partes em que se divide o primeiro tomo, isto é, a que trata dos escritores, está saindo em uma revista estrangeira, a Nueva Revista de Buenos Aires, para a qual estou colaborando por muitas instâncias dos respectivos fundadores, os Drs. Vicente Quesada e Ernesto Quesada, escritores de reputação bem estabelecida.

Já remeti para ali as rápidas biografias dos Srs. Inglês de Souza, Santa Helena Magno, Júlio César e a sua. A ordem seguida é geográfica. O primeiro dos indicados escritores representa a província do Amazonas e os três últimos o Pará.

A Nueva Revista é colaborada pelos primeiros escritores da América Latina. É uma das melhores produções do nosso continente. O Sr. Ernesto Quesada com quem me correspondo epistolarmente, é o tradutor dos meus escritos.

Se o colega quiser que seja publicado em tão importante revista algum trabalho seu, mande-me o que terei muita satisfação em transmiti-lo ao Dr. Quesada.

Já fiz ver a este a conveniência de remeter para o Pará a sua Revista a fim de ser aí conhecida ${ }^{18}$.
\end{abstract}

O fragmento acima revela aspectos importantes acerca da circulação de ideias e das transferências culturais operacionalizadas por Vicente e Ernesto Quesada por meio da Nueva Revista de Buenos Aires. A tradução de textos originais, bem como a abertura à colaboração de intelectuais de diferentes nacionalidades, fez do periódico argentino um pioneiro ao colocar em prática um projeto bem sucedido de estreitamento de laços, de trocas e de cooperação intelectual entre os países latino-americanos.

Franklin Távora continuou a manter José Veríssimo informado sobre a publicação de seu perfil na revista argentina e atuou como intermediário a fim de viabilizar a chegada de uma coleção da Nueva Revista de Buenos Aires às mãos do escritor paraense:

\footnotetext{
${ }^{18}$ Franklin Távora. Carta a José Veríssimo, datada do Rio de Janeiro, em 17 de agosto de 1882. Cf. Arquivo da Academia Brasileira de Letras (Pasta 27-1-18).
}

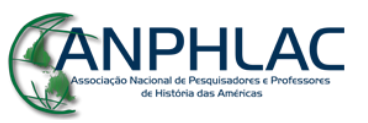


O seu rápido perfil que, há 3 ou quatro meses, está com o redator da Nueva Revista de Buenos Aires deve sair no fascículo de 1 de março (próximo). Já estão publicados os dos Srs. Inglês de Souza, Santa Helena (pobre amigo!), e Júlio César.

Ao mesmo redator já escrevi comunicando-lhes as suas ordens quanto à assinatura da Nueva Revista.

Abraça-o seu amigo e admirador, Franklin Távora. ${ }^{19}$

No fascículo da Revista de Buenos[Aires] de abril corrente saiu a sua biografia.

O Dr. Ernesto Quesada pede-me encarecidamente lhe obtenha um agente aí. Será possível? Por falta de agente ali, ou aqui, não seguiu a coleção que o colega pede.

Remeto-lhe a incluída carta do Dr. Quesada na qual se refere ao colega. Peço-lhe que me devolva, visto que contêm a autorização para a impressão sobre os literatos do Norte $^{20}$.

A relação entre Franklin Távora e os editores argentinos manteve-se exclusivamente por meio de correspondências até o ano de 1883, quando ocorreu o primeiro encontro entre eles na cidade do Rio de Janeiro. Vicente Quesada havia iniciado sua carreira diplomática no país e não tardou a enfronhar-se nos círculos culturais cariocas, culminando com a sua participação em uma festa literária, que repercutiu na imprensa brasileira e argentina.

\section{A festa literária de 1883 e a confraternização latino-americana no Rio de Janeiro.}

Vicente Quesada considerava que as relações entre os países do continente obedeciam a interesses específicos e concretos, sobretudo de caráter material, mas entendiam que se tratavam de vínculos que, para serem autenticamente frutíferos, deviam estar articulados e mediados por um conhecimento mútuo das ideias e culturas que informavam as elites dirigentes. Assim, desde o início da sua carreira diplomática, procurou integrar-se às instituições científicas e culturais mais relevantes em cada país.

Em sua estadia no Rio de Janeiro, entre os anos de 1883 e 1885, como Enviado Extraordinário e Ministro Plenipotenciário da República Argentina, Quesada participou de jantares e reuniões literárias, sendo inclusive motivo de uma festa que reuniu intelectuais, políticos e a família real brasileira, realizada em 30 de agosto de 1883. A cerimônia recebeu

\footnotetext{
${ }^{19}$ Franklin Távora. Carta a José Veríssimo, datada do Rio de Janeiro, em 27 de fevereiro de 1883. Cf. Arquivo da Academia Brasileira de Letras (Pasta 27-1-18).

${ }^{20}$ Franklin Távora. Carta a José Veríssimo, datada do Rio de Janeiro, em 21 de abril de 1883. Cf. Arquivo da Academia Brasileira de Letras (Pasta 27-1-18).
}

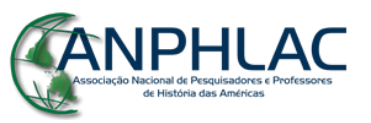

Revista Eletrônica da ANPHLAC, ISSN 1679-1061, №. 21, p. 209-231, Jul./Dez., 2016.

http://revista.anphlac.org.br 
destaque na imprensa carioca, na Nueva Revista de Buenos Aires e também foi descrita no livro Mis memórias diplomáticas, de autoria de Vicente Quesada, publicado em 1908. Ocuparemonos de trechos dos discursos proferidos naquela ocasião que salientaram a atuação dos Quesada como mediadores culturais, bem como a recepção de tais ideias pelos interlocutores brasileiros.

Relembrando aquele episódio, Vicente Quesada afirmou que ele próprio já havia falado ao imperador do Brasil sobre quão proveitoso seria promover as relações literárias entre os países latino-americanos. (QUESADA, 1908, p. 213-214) Em sintonia com este propósito, o brasileiro Franklin Távora organizou uma festa literária por motivo da estadia do representante argentino no país. Ernesto Quesada, que se encontrava no Rio de Janeiro em visita ao pai, também foi convidado para o evento, no qual se objetivava também a fundação de uma Associação dos literatos do Brasil. A Nueva Revista de Buenos Aires deu grande publicidade à cerimônia e transcreveu os discursos de João Manuel Pereira da Silva, político e literato brasileiro, de Vicente Quesada, Ernesto Quesada e de Franklin Távora. Em todos os discursos, ressaltou-se os benefícios do estreitamento dos laços culturais entre os vizinhos americanos e de um maior intercâmbio de livros e textos entre os homens de letras do continente.

Os oradores demonstraram um amplo conhecimento em relação às obras de seus pares argentinos. Destacamos a referência sobre a atuação dos Quesada na direção da Nueva Revista de Buenos Aires que, de acordo com Távora, era conhecida e apreciada por quase toda imprensa diária da capital imperial. ${ }^{21}$

Os intelectuais brasileiros e argentinos estavam afinados também quanto à concepção de que o desenvolvimento econômico do continente deveria estar atrelado ao fomento das atividades culturais, pois estas constituíam a "alma, o farol, a bússola, a verdadeira potência para garantir a existência sábia e honrada dos povos e para facilitar os progressos, que lhes cumpre alcançar em sua marcha singular e em seu glorioso destino". (João Manuel Pereira da Silva Apud QUESADA, 1908, p. 227) A proposta de fundação de uma associação literária foi bastante exaltada devido à perspectiva da promoção de intercâmbio entre os centros literários da América Latina e do fomento de leitores; vislumbrava-se a criação de bibliotecas

\footnotetext{
${ }^{21}$ No convite oficial para o evento, transcrito por Vicente Quesada no livro Mis memórias diplomáticas, também constavam referências à Nueva Revista de Buenos Aires, apresentada como uma "importante publicação na qual as letras americanas encontram boa acolhida". Cf. QUESADA, 1908, p. 208.
}

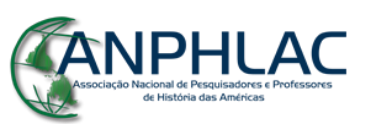

Revista Eletrônica da ANPHLAC, ISSN 1679-1061, №. 21, p. 209-231, Jul./Dez., 2016.

http://revista.anphlac.org.br 
exclusivamente americanas e a maior circulação de revistas, a fim de despertar o gosto pelo conhecimento da produção intelectual dos países vizinhos.

Vicente Quesada, reverberando a conjuntura social argentina, refletiu sobre a consonância entre literatura e identidade. Chamou a atenção para a quantidade de imigrantes que adentravam no continente americano e para a necessidade de assimilá-los à população nativa para dar unidade às nações americanas. Quesada destacou também as particularidades das nações do continente americano:

\begin{abstract}
Nosotros pertenecemos, como naciones, á la tierra nueva, y nuevos son los obstáculos y nuevas nuestras exigencias, y por todo ello deben ser nuevas las soluciones que debemos buscar todos los americanos sin distinción de nacionalidad, puesto que son intereses y necesidades peculiares de América (...) Lo reconozco y lo confieso; la base de nuestra civilización es europea, y nuestro presente se halla vinculado á Europa; por ello, cuando hablo del sentimiento y del espíritu americano, no intento afirmar que sea antagónico ni contrario á Europa: no (...) Pero repito: nuestros problemas sociales y económicos no son los mismos que agitan y apasionan la opinión pública en Europa. Nuestra historia es distinta y nuestras peculiaridades nos diversifican. (QUESADA, 1908, p. 233-234)
\end{abstract}

Ernesto Quesada, em seu discurso, chamou a atenção para as similaridades que vinculavam os países latino-americanos naquela conjuntura, uma vez que pertenciam à mesma raça e religião, possuíam os mesmos costumes, eram limítrofes e tinham problemas idênticos a resolver. Não obstante, lamentava o profundo isolamento intelectual e material em que viviam. De acordo com ele, os literatos destes países deveriam unir esforços para reverter essa situação. Demonstrando eloquência e amplo conhecimento da produção intelectual latino-americana, Ernesto Quesada discorreu sobre a inegável influência europeia no continente, porém ressaltou o vigor da vida intelectual americana e a necessidade de se difundir esses trabalhos.

\title{
Considerações finais.
}

As ideias expostas na referida festa literária sintetizaram objetivos que já estavam postos na Nueva Revista de Buenos Aires. Vicente e Ernesto Quesada tinham como principal intento a manutenção de uma revista cultural que refletisse o anseio de delimitar o lugar da cultura argentina e latino-americana, com suas especificidades e originalidade.

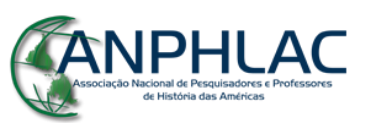


Movidos por uma aventada "missão patriótica", os Quesada se mobilizaram no sentido de orientar e ordenar os elementos que comporiam uma cultura argentina genuinamente nacional. Nesta, deveriam situar-se aspectos inerentes a todas as províncias do país, rechaçando assim interpretações que colocavam a tônica da história e da literatura exclusivamente em Buenos Aires. As temáticas apresentadas nas colaborações estrangeiras estavam intrinsecamente ligadas ao programa da Nueva Revista de Buenos Aires. Neste ensejo, a Argentina foi apresentada como catalisadora das inquietações latino-americanas. Buscava-se, assim, demonstrar aos leitores as similaridades das discussões intelectuais levadas a cabo pelo periódico platino e aquelas presentes nos demais países latino-americanos.

Não obstante, a Nueva Revista de Buenos Aires viabilizou um grande fluxo de intercâmbios culturais na década de 1880, divulgando resenhas de livros, artigos originais e transcrições assinadas por intelectuais de diversos países latino-americanos, pontuadas por declarações significativas em prol do estreitamento das relações no continente. Os artigos de Franklin Távora e seu posicionamento na confraternização literária de 1883 denotam o diálogo mantido por meio da Nueva Revista de Buenos Aires. Tanto para Távora, quanto para os Quesada, era momento de orientar o olhar para o interior de seus países em face aos estrangeirismos - ou cosmopolitismo, como convencionou-se chamar na Argentina -, característicos de países com passado colonial e que se deparavam naquela conjuntura com ondas imigratórias. Este movimento, por sua vez, descortinava as singularidades e a riqueza cultural do continente americano, que deveriam ser exaltadas e conhecidas por todos.

\section{Referências bibliográficas}

AGUIAR, Cláudio. Franklin Távora e o seu tempo. São Caetano do Sul: Ateliê Editorial, 1997.

ALONSO, Paula. "En la primavera de la historia". El discurso político del roquismo de la década del ochenta a través de su prensa. Boletín del Instituto de Historia Argentina y Americana "Dr. Emilio Ravignani”. Tercera serie, n. 15, p. 35-70, 1997.

BERTONI, Lilia Ana. Patriotas, cosmopolitas y nacionalistas. La construcción de la nacionalidad argentina a fines del siglo XIX. Buenos Aires: Fondo de Cultura Económica de Argentina, 2001.

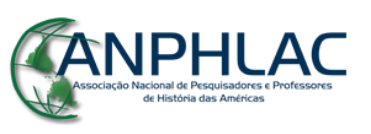


BUCHBINDER, Pablo. Los Quesada. Letras, ciencias y política en la Argentina, 1850-1934. Buenos Aires: Edhasa, 2012.

CHARTIER, Roger. Texto, impressão, leituras. In: HUNT, Lynn. A nova história cultural. São Paulo: Martins Fontes, 1992.

DARNTON, Robert. Os best-sellers proibidos da França pré-revolucionária. São Paulo: Companhia das Letras, 1998.

DAVIDSON, Cathy N. Reading in America: literature and social history. Baltimore: John Hopkins University Press, 1989.

E. O. A. Las revistas en América - Revista Brazileira - Revista de Chile - Los literatos en la República Argentina. Nueva Revista de Buenos Aires. Buenos Aires, Tomo V, p. 454-461, 1882.

ESPAGNE, Michel. Les transferts culturels Franco-Allemands. Paris: Presses Universitaires de France, 1999.

GÁLVEZ, Victor. Memorias de un viejo. Escenas de costumbres de la República Argentina. Buenos Aires: Jacobo Peuser Editor, 1889.

HABERMAS, Jürgen. Mudança estrutural da esfera pública. Rio de Janeiro: Tempo Brasileiro, 1984.

HOBSBAWM, Eric J. Nação e nacionalismo desde 1870. Rio de Janeiro: Paz e Terra, 2002.

PASTORMERLO, Sergio. 1880-1899. El surgimiento de un mercado editorial. In: DE DIEGO, José Luis. Editores y políticas editoriales en Argentina (1880-2010). $2^{a}$ ed., Buenos Aires: Fondo de Cultura Económica, 2014.

PRIETO, Adolfo. El discurso criollista en la formación de la Argentina moderna. Buenos Aires: Editorial Sudamericana, 1988.

RACOT, Adolf. Las etapas de la Revista de Ambos Mundos. Nueva Revista de Buenos Aires. Buenos Aires: Imprenta própia, p. 129-151, Tomo X, 1884.

RAMÍREZ BRASCHI, Dardo. Vicente G. Quesada y sus vínculos con la provincia de Corrientes. Anales de la Junta de Historia de la Província de Corrientes. Corrientes: Moglia Ediciones, 2004.

Revista Bibliográfica. Nueva Revista de Buenos Aires. Buenos Aires: Imprenta y Libreria de Mayo, p. 195-204, Tomo II, 1881.

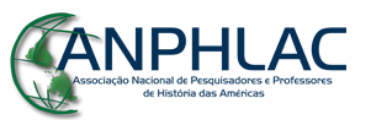

Revista Eletrônica da ANPHLAC, ISSN 1679-1061, №. 21, p. 209-231, Jul./Dez., 2016.

http://revista.anphlac.org.br 
ROMERO, Silvio. Literatura brasileira. Sus relaciones con el "neo-realismo". Nueva Revista de Buenos Aires. Buenos Aires, Tomo III, p. 483-507, 1882.

QUESADA. Ernesto. El movimiento intelectual argentino: revistas y periódicos. Nueva Revista de Buenos Aires. Buenos Aires, Tomo V, p. 462-475, 1882.

1884.

. Dos palabras. Nueva Revista de Buenos Aires. Buenos Aires, Tomo X, p. 03-10,

QUESADA, Vicente. Prospecto. Nueva Revista de Buenos Aires. Buenos Aires, tomo I, 1881.

. Mis Memorias Diplomáticas. Misión ante el gobierno del Brasil. Buenos Aires: Imprenta de Coni Hermanos, 1908.

SABATO, Hilda. La vida pública en Buenos Aires. In: BONAUDO, Marta (org.). Nueva historia argentina: liberalismo, estado y el orden burgués (1852-1880). Buenos Aires: Sudamericana, 1999.

SEVCENKO, Nicolau. Literatura como missão. Tensões sociais e criação cultural na Primeira República. São Paulo: Companhia das Letras, 2003.

SHUMWAY, Nicolas. A invenção da Argentina: História de uma ideia. São Paulo: Editora da Universidade de São Paulo; Brasília: Editora UnB, 2008.

SOARES. Gabriela Pellegrino. História das ideias e mediações culturais: breves apontamentos. In: JUNQUEIRA, Mary Anne; FRANCO, Stella Maris Scatena (orgs.) Cadernos de Seminários de Pesquisa. vol. 2. São Paulo: Departamento de História da Faculdade de Filosofia, Letras e Ciências Humanas. Universidade de São Paulo/Humanitas, 2011.

Suplemento a la entrega de março de 1882 de la "Nueva Revista". Nueva Revista de Buenos Aires. Buenos Aires: Imprenta y Libreria de Mayo, Tomo II, 1882.

TÁVORA, Franklin. La literatura brasileira. Escritores del Norte del Brasil. Nueva Revista de Buenos Aires. Buenos Aires: Imprenta y Libreria de Mayo, p. 221-239, Tomo V, 1882.

TERÁN, Oscar. Vida intelectual en el Buenos Aires fin-de-siglo (1880-1910). Derivas de la "cultura científica". Buenos Aires: Fondo de Cultura Económica, 2000.

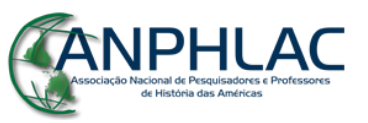

Revista Eletrônica da ANPHLAC, ISSN 1679-1061, №. 21, p. 209-231, Jul./Dez., 2016.

http://revista.anphlac.org.br 